\title{
Substances use and its association with socio-demographic, family, and environment-related factors among technical and vocational education and training college students in Ataye, Ethiopia; an institution-based cross-sectional study
}

\author{
Abate Dargie Wubetu ${ }^{1 *}$, Sintayehu Getachew ${ }^{2}$ and Wassie Negash ${ }^{1}$
}

\begin{abstract}
Background: Legal substances use is prevalent in Ethiopia. Substance use can have several health problems that are potentially harmful to educational performance, social issues, psychological and physical wellbeing. This study aimed to know the prevalence of lifetime and last month's substance use and its associated factors among technical and vocational education and training College students in Ataye town.

Methods: An institution-based cross-sectional study was conducted from 1 March to last May 2019. Participants were selected using a simple random sampling technique. Data collected by using a structured and pretested interviewer-administered questionnaire. Data collected by five trained diploma nurses with close supervision. Odds ratio with their $95 \%$ confidence interval, and $p$-value less than 0.05 used to declare the statistical significance of associated factors.

Results: Four hundred eighty-three individuals participated in the study, which was a response rate of $94 \%$. The prevalence of lifetime legal substance use was 32.5\% (95\% Cl: 28.2, 36.5). The prevalence of last month's legal substances use was $21.9 \%(95 \% \mathrm{Cl}=18.2,25.5)$. Among lifetime legal substance users, the majority $(25.5 \%)$ chewed khat. The others, (19.5\%) drunk alcohol, and, 15.3\% smoked cigarettes in a lifetime. Lifetime cannabis and cocaine users were 2.5 , and $7.2 \%$ respectively. Among last month's legal substance users, (21.9\%) chewed khat followed by alcohol drinking (16.6\%), and cigarette smoking (15.3\%). In the last month, 1.2 and 3.3\% of students used cannabis and cocaine respectively. Multivariate logistic regression showed that being male, having a divorced family, living greater than 20 years in the town, having substance user family members, having intimate friend substance users, and easy availability of substances were independent predictors of lifetime legal substances use.
\end{abstract}

* Correspondence: abatedargie2001@gmail.com; abatedargie@dbu.edu.et 'Department of Nursing, College of Health Science and Medicine, Debre Berhan University, P.O. Box 445, Debre Berhan, Ethiopia

Full list of author information is available at the end of the article

C C The Author(s). 2020 Open Access This article is licensed under a Creative Commons Attribution 4.0 International License, which permits use, sharing, adaptation, distribution and reproduction in any medium or format, as long as you give appropriate credit to the original author(s) and the source, provide a link to the Creative Commons licence, and indicate if changes were made. The images or other third party material in this article are included in the article's Creative Commons licence, unless indicated otherwise in a credit line to the material. If material is not included in the article's Creative Commons licence and your intended use is not permitted by statutory regulation or exceeds the permitted use, you will need to obtain permission directly from the copyright holder. To view a copy of this licence, visit http://creativecommons.org/licenses/by/4.0/. The Creative Commons Public Domain Dedication waiver (http://creativecommons.org/publicdomain/zero/1.0/) applies to the data made available in this article, unless otherwise stated in a credit line to the data. 


\begin{abstract}
(Continued from previous page)
Conclusions: The prevalence of last month and lifetime legal substance use at Ataye Technical and Vocational Education and Training (TVET) college students were analogous with most studies done in Ethiopia. It is advisable if the college administrators work together with town administrators to mitigate the problem including closing substance use houses around the school. Overall, Substance use among adolescents should get further emphasis to lower the prevalence.
\end{abstract}

Keywords: Prevalence, Lifetime, Last month, Substance use, College students

\section{Background}

Substance use has the capability of affecting the state of the body and the mind by either depressing or stimulating the central nervous system or producing other biochemical harmful effects [1-3]. An estimated $5 \%$ of the global adult population use drugs at least once in their lifetime as studied in 2015. The more worrisome fact is about $0.6 \%$ of the global adult population suffers from drug use disorders [4].

World drug report revealed that more than a quarter of a billion people use drugs globally. Roughly, almost half a million people died because of drug use in 2015, according to the World Health Organization (WHO). Of those deaths, nearly $170,000(2.7 \%)$ deaths directly associated with drug use disorders (mainly overdoses), [5].

According to the Ethiopian Demographic and Health Survey (EDHS) report, one-third of women and about half of men reported drinking alcohol at some point in their lives. The proportion of legal substances use is increasing every year in both sexes. The use of tobacco increases with the age of men. There is a wide regional variation in cigarette smoking in Ethiopia [6].

Drug use is associated with adverse health consequences. Problems of substance use seem to be a rapidly growing concern globally. It is also a major threat among youth in college and university. Some of the researchers have shown that the use of drugs by school-going youth does not only decrease their academic performance; but also makes them vulnerable to crime. Furthermore, drug use exposes them to health risks among other numerous problems [7-13].

Substances use is a common phenomenon among students in Ethiopia. It has also been noted that family background, student pocket money, peer pressure, accessibility of substances, and customs of society contribute to the increased rate of substance use among college students. Most students, staffs at an institution of higher education, and youths in the community considered are at high risk of substance use, [14-20].

The problem of substance use has historically been linked to Ataye town due to the accessibility of substances. Khat use is a common phenomenon in the study area [17]. Even though such problems are one of the top health risks among college students, there are no adequate studies conducted to explore the prevalence and associated factor of a lifetime and last month's substance use in technical and vocational education and training (TVET) college students. The findings of this study will be useful to the education bureau and school administrations to develop strategies to mitigate students' substance use behavior. The study findings also may help curriculum developers in formulating and incorporating psychoeducation programs in TVET College that address the risk of substance use. School managers also may benefit from findings so that they may come up with policies and strategies for controlling this potentially dangerous habit.

The main aim of this study was to assess the lifetime and last month prevalence of substance use and to identify associated factors with it. Each type of substance use proportions was also described.

\section{Methods \\ Study area}

The study was conducted at Ataye TVET College. Ataye TVET College was found in the North Showa zone that found in Amara Regional state of Ethiopia. The study area is located $272 \mathrm{~km}$ from Addis Ababa and $130 \mathrm{~km}$ from Debre Berhan town. Orthodox, Muslim, and protestant followers are the major inhabitants found in the study area. At Ataye TVET College, there are 1433 students enrolled in the academic year. Out of these, 683 were male, and 750 were female students.

\section{Study design, and period}

An institution-based cross-sectional study was conducted from 1 March to last May 2019.

\section{The study participants}

There are nine departments from the first year to the third year. The departments are Agriculture, hotel kitchen operation, Electricity, Auto engine service, Garment, Surveying, Construction, Metalwork, and Road construction. All regular Ataye TVET college students, and who were available during the study period considered as the study population. Students could not reach in three visits during the data collection period excluded from the study. 


\section{Study variables \\ Dependent variables}

Lifetime and last month substance use.

\section{Independent variables}

Socio-demographic characteristics: (age, sex, residence, economic status, education status, religion, ethnicity, and, living status, mother education level, father education level, and having substance user friend, lack of family supervision, family conflict, family history of substance use, family income, availability of substance, source of money, grade level, peer pressure, marital status of the family.

\section{Sample size determination}

The sample size was calculated using a single population proportion formula. A $15.36 \%$ rate of substance use was taken from the related study [17], with a margin of error $5 \%$, confidence level $95 \%$, and non-response rate $10 \%$. The final sample size became 514 students.

\section{Sampling technique, and procedure}

Out of nine departments, five departments (55\%) selected by using the lottery method. Ataye TVET College has 1433 students enrolled in the study academic year. The study participants selected by using a simple random sampling technique by generating random numbers using Open EPI software.

\section{Method of data collection, and tools}

Data were collected by using a structured and interviewer-administered questionnaire. The questionnaire included variables like a lifetime and last month's substance use, socio-demographic, and economic factors, the practice of substance use, the reason for substance use, and family history of substance use. The questionnaire of independent factors was assessed by using questionnaires adapted from reviewing similar related articles. The outcome variables (lifetime, and last month substance use) were assessed by using the first two sections of the English version of Alcohol, Smoking, and Subtance Involment Screening Test (ASSIST) tool [21] "yes"/ No questions. Lifetime substance use assessed by asking "Have you ever use one of the following substances, and if yes which type of substance use you can circle more than one option?". Last month substance use was also assessed by asking, "have you use one of the following substances in the last 30 days, and if yes, which type of substance; you can circle more than one option?"

\section{Data quality assurance}

The questions were translated into the local language (Amharic). To keep the quality of data, data collectors and supervisors trained for 1 day regarding the necessary explanation about the current research. Data collected by five trained diploma nurses with close supervision. A pre-test was conducted on $5 \%(n=24)$ students among similar study populations from non-participating departments before 2 weeks of the actual data collection period. After the pretest, the wording and the sharpness of the questions were modified. The collected data were reviewed and checked for completeness before data entry. The data properly coded and entered into Epi Info 3.5.1 and exported to SPSS V. 21 for analysis.

\section{Operational definitions \\ Lifetime legal substance use}

Use of one or more legal substances (Ethiopia context) for nonmedical purposes (alcohol, khat, and cigarette) after joining the Ataye TVET College.

\section{Last month legal substance use}

Use of one or more legal substances (Ethiopia context) for nonmedical purposes (alcohol, khat, and cigarette) in the past 30 days before the data collection period.

\section{Legal substances}

Drugs are not prohibited from selling, buying, and using among above 18 years old persons (alcohol, khat, and cigarette) during the study period.

\section{Illegal drugs}

Drugs, which prohibited from selling, buying, and using among all age groups (cocaine and cannabis) during the study period.

\section{Data processing, and analysis}

Lifetime and last month's legal substance use were the dependent variables. Each substance use in a lifetime and last month were investigated and discussed in the discussion section. Illegal substance use prevalence was assessed as additional information. Socio-demographic, and economic factors, the practice of substance use, the reason for substance use, and family history of substance use were the independent variables of the study. The missed data were not encountered in this study. Variance Inflation Factor (VIF) was calculated for each collinear variable and its value ranges from two up to three. Bivariate comparison and statistical significance of differences were tested by the chi-square test. Bivariate and multivariate binary logistic regression analysis was performed to identify associated factors. The backward logistic regression method was used. Odds ratio with their $95 \%$ confidence interval and $p$-value less than 0.05 considered to declare the statistical significance of associated factors. 


\section{Ethical consideration}

Ethical clearance obtained from the Debre Berhan University ethical review committee. A letter of cooperation wrote to each study institution, and a permission letter taken from the study institutions. The data collectors took oral informed consent from each study participant, whose age is 18 years and above. Moreover, the data collectors took assent from participants whose age was less than 18 years. Written informed consent taken from participants' family/ legal guardian whose age was less than 18 years.

\section{Results}

\section{Prevalence's of substances use}

Four hundred eighty-three individuals participated in the study, which was a response rate of $94 \%$. The prevalence of lifetime legal substance use was 32.5\% (95\% CI: 28.2, 36.5). The prevalence of last month's legal substances use was $21.9 \%(95 \% \mathrm{CI}=18.2,25.5)$. Among lifetime legal substance users, the majority $(25.5 \%)$ chewed khat. The others, (19.5\%) drunk alcohol, and, 15.3\% smoked cigarettes in a lifetime. Lifetime cannabis and cocaine users were 2.5 , and $7.2 \%$ respectively. Among last month's legal substance users, (21.9\%) chewed khat followed by alcohol drinking (16.6\%), and cigarette smoking (15.3\%). In the last month, 1.2 and 3.3\% of students used cannabis and cocaine respectively.

\section{Sociodemographic characteristics of students}

Four hundred eighty-three students participated in the study, which was a response rate of $94 \%$. The median age of the students was 20 years with an interquartile range of three, $(\mathrm{Q} 1=18, \mathrm{Q} 3=21$ years $)$. Among the socio-demographic variables, a nearly equal proportion was observed in terms of sex $(49.7 \%$ male and $50.3 \%$ female). The majority, (71.6\%) students were orthodox in religion and the remaining (28.4\%), and (4.1\%) were Muslim and protestant respectively. The higher proportion, $(60.5 \%)$ of students were from the Amhara region and the remaining were from Tigray, (18\%) and, (12\%) from the Oromia region. Almost half of the students, (47\%) were level-I in academics. The remaining (14.7\%), (26.3\%), and (12\%) of students were Level, II, III, IV in academic level respectively. Almost, a similar proportion of students lived alone (42.4\%), and with family (40.2\%). Others, (17.4\%) lived with peers. Almost $69 \%$ of students, (68.5\%) earn average monthly pocket money of greater than 200 ETB (Ethiopian Birr) and the left earn less than 200 ETB. The highest proportion of students, (95.4\%) were from an urban area and, (4.6\%) from a rural area.

Family-related factors of lifetime legal substances used Almost half, (57.4\%), and (52\%) of student's mother and father not attended modern education respectively. Sixty percent of student's parents lived in an urban area, and (44\%) was a farmer in occupation. Nearly $80 \%$ of students' parents were married and nearly $40 \%,(43.1 \%)$ of student's parents lived for 1-5 years in the Ataye town (Table 1).

\section{Environmental factors of substances use}

There are many houses opened by merchants in the study area for substance use in-group. The majority, (90\%) of TVET students reported, "They used both the legal and illegal substances at substance use houses."

Table 1 Family-related factors of lifetime legal substances use among Ataye TVET students, north Shoa zone, Ethiopia, 2019

\begin{tabular}{|c|c|c|c|}
\hline \multirow[t]{2}{*}{ Variables } & \multicolumn{2}{|c|}{ Lifetime substance use } & \multirow[t]{2}{*}{$P$-value } \\
\hline & Yes (\%) & No (\%) & \\
\hline \multicolumn{4}{|c|}{ Mother's educational level } \\
\hline No education & 75 (15.6) & $202(41.8)$ & 0.001 \\
\hline Grade 1-12 & $42(8.6)$ & $71(14.8)$ & \\
\hline College & $40(8.2)$ & $53(11)$ & \\
\hline \multicolumn{4}{|c|}{ Father's educational level } \\
\hline No education & $65(13.5)$ & $186(38.5)$ & 0.003 \\
\hline Grade 1-12 & $39(8.1)$ & $68(14)$ & \\
\hline college & $53(11)$ & $72(14.9)$ & \\
\hline \multicolumn{4}{|l|}{ Family residency } \\
\hline Rural & $70(14.5)$ & $123(25.5)$ & 0.150 \\
\hline Urban & $87(18)$ & $203(42)$ & \\
\hline \multicolumn{4}{|l|}{ parents job } \\
\hline Government & $47(9.7)$ & $122(25.3)$ & 0.004 \\
\hline Farmer & $63(13)$ & $149(31)$ & \\
\hline Merchant & $47(9.7)$ & $55(11.4)$ & \\
\hline \multicolumn{4}{|c|}{ Family monthly income (ETB) } \\
\hline$<1000$ & $21(4.4)$ & $87(18)$ & 0.001 \\
\hline $1001-1500$ & $26(5.4)$ & 90 (18.6) & \\
\hline $1501-2000$ & $17(3.5)$ & $60(12.5)$ & \\
\hline$>2000$ & $93(19.3)$ & $89(18.4)$ & \\
\hline \multicolumn{4}{|l|}{ Parent marital status } \\
\hline Married & $88(18.2)$ & $208(43.1)$ & 0.001 \\
\hline Widowed/widower & $11(2.3)$ & $19(3.9)$ & \\
\hline Divorced & $58(12)$ & $19(3.9)$ & \\
\hline \multicolumn{4}{|l|}{ Years living in the town } \\
\hline $1-5$ & $70(14.5)$ & $138(28.6)$ & 0.001 \\
\hline $6-10$ & $19(3.9)$ & $77(16)$ & \\
\hline $11-15$ & $7(1.5)$ & $33(6.8)$ & \\
\hline $16-20$ & $29(6)$ & $63(13)$ & \\
\hline$>20$ & $32(6.6)$ & $15(3.1)$ & \\
\hline \multicolumn{4}{|c|}{ Having substance user family } \\
\hline Yes & $72(14.9)$ & $20(4.1)$ & 0.001 \\
\hline No & $85(17.6)$ & $306(63.4)$ & \\
\hline
\end{tabular}


The remaining reported they use the substances with their family at their own living houses. Among the total students, $(61.5 \%)$ reported that they start to use legal substances in their lifetime due to easily available in their hometown. Similar proportions (40\%) of both lifetime and last month legal substance users reported "They started substance use due to need of energy to read" academic issues. Students reported additional environmental factors for their lifetime and last month's legal substance use, (Fig. 1).

\section{Lifetime and last month legal substance use and its correlates}

The lifetime prevalence of legal substance use was 32.5\% (95\% CI: 28.2, 36.5). Among lifetime users, the majority (25.5\%) chewed Khat; followed by alcohol drinking (19.5\%). Students in different age groups did not equally experience legal substance use in a lifetime. Being from the urban and rural areas had not contributed to both lifetime and last month's legal substance use. However, other predictor variables were statistically significant with the association of lifetime alcohol, khat, and cigarette use. This implied that students in different categories of the variables were not equally practiced the use of the listed legal substances in a lifetime.

The prevalence of last month's substance use was $21.9 \%$ (95\% CI $=18.2$, 25.5). Among last month's substance users, the same proportions (21.9\%) chewed khat; followed by alcohol drinking, (16.6\%), and cigarette smoking, (15.3\%).

Alcohol, khat, and cigarette use in the last month and its variation across study subjects' characteristics compared using chi-square with its $p$-value. The result of this study showed that being in different age groups had a contribution to the prevalence of last month's licit substance use. Being from urban and rural in residency was statistically insignificant for all the three listed drugs (alcohol, khat, and cigarette). This means students in these subcategories equally practiced substances use in the last month. Living alone and living with others had a contribution to the variation of last month's prevalence of alcohol drinking $(p$-value $=0.02)$ and Khat chewing $(p$ value $=0.001)$, but not for cigarette smoking $(p$-value $=$ 0.2 ). All the reported predictor variables of the students were statistically significant correlates with last month's substance use. This indicated that students with different predictor variables were not equally practiced drugs in the last month (Table 2).

\section{Lifetime and last month illegal substance use and its correlates}

The prevalence of lifetime use of cannabis and cocaine was 2.5 and $7.2 \%$ respectively. Additionally, 1.2 and 3.3\% of students used cannabis and cocaine in the last month respectively.

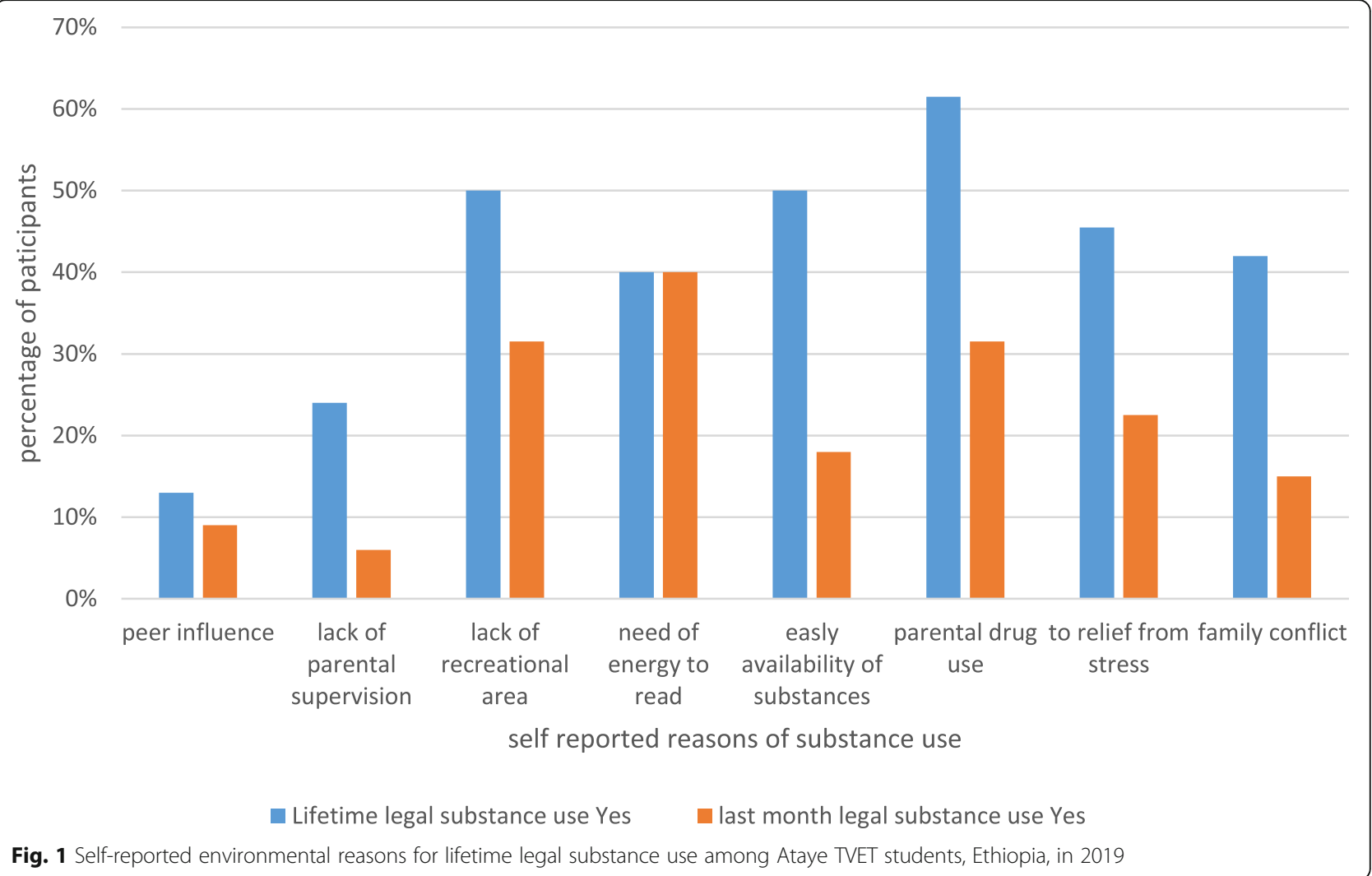


Table 2 Lifetime legal drugs use and its correlation with students and family characteristics among Ataye TVET college students, Ethiopia, 2019

\begin{tabular}{|c|c|c|c|c|c|c|}
\hline \multirow[t]{2}{*}{ Variables } & \multicolumn{2}{|c|}{ Lifetime alcohol use } & \multicolumn{2}{|c|}{ Lifetime khat use } & \multicolumn{2}{|c|}{ Lifetime cigarette use } \\
\hline & Yes (\%) & $P$-value & Yes (\%) & $P$-value & Yes (\%) & $P$-value \\
\hline \multicolumn{7}{|l|}{ Age in years } \\
\hline$<18$ & $3(0.6)$ & 0.001 & $1(0.2)$ & 0.001 & $1(0.2)$ & 0.001 \\
\hline 18-19.9 & $21(4.4)$ & & $30(6.2)$ & & $15(3.1)$ & \\
\hline $20-21$ & $43(8.9)$ & & $61(12.7)$ & & $38(7.9)$ & \\
\hline$>21$ & $13(2.7)$ & & $14(2.9)$ & & $76(15.8)$ & \\
\hline \multicolumn{7}{|l|}{ Sex } \\
\hline Male & $1(0.2)$ & 0.001 & 80 (16.6) & 0.001 & $49(10.2)$ & 0.001 \\
\hline Female & $62(12.9)$ & & $26(5.4)$ & & $14(2.9)$ & \\
\hline \multicolumn{7}{|l|}{ Residency } \\
\hline Urban & $76(15.8)$ & 0.80 & $102(21.2)$ & 0.70 & $60(12.5)$ & 0.90 \\
\hline Rural & $4(0.8)$ & & $4(0.8)$ & & $3(0.6)$ & \\
\hline \multicolumn{7}{|c|}{ Living years in the town } \\
\hline $1-5$ & $33(6.9)$ & 0.006 & $43(8.9)$ & 0.001 & $24(5.0)$ & 0.004 \\
\hline $6-10$ & $10(2)$ & & $15(3.1)$ & & $7(1.5)$ & \\
\hline $11-15$ & $4(0.8)$ & & $5(1.0)$ & & $4(0.8)$ & \\
\hline $16-20$ & $17(3.5)$ & & $19(3.9)$ & & $14(2.9)$ & \\
\hline$>20$ & $16(3.3)$ & & $24(5.0)$ & & $14(2.9)$ & \\
\hline \multicolumn{7}{|l|}{ Academic level } \\
\hline level one & $16(3.3)$ & 0.001 & $16(3.3)$ & 0.001 & $8(1.7)$ & 0.001 \\
\hline level two & $13(2.7)$ & & $29(6.0)$ & & $17(3.5)$ & \\
\hline level three & $28(5.8)$ & & $38(7.9)$ & & $20(4.2)$ & \\
\hline level four & $23(4.8)$ & & $23(4.8)$ & & $18(3.7)$ & \\
\hline \multicolumn{7}{|l|}{ Currently living } \\
\hline Alone & $38(7.9)$ & 0.02 & $52(10.8)$ & 0.001 & $30(6.2)$ & 0.20 \\
\hline with family & $22(4.6)$ & & $26(5.4)$ & & $19(3.9)$ & \\
\hline with peers & $20(4.2)$ & & $28(5.8)$ & & $14(2.9)$ & \\
\hline \multicolumn{7}{|c|}{ Family monthly income (ETB) } \\
\hline$<1000$ & $8(1.7)$ & 0.001 & $8(1.7)$ & 0.001 & $5(1.0)$ & 0.001 \\
\hline $1001-1500$ & $15(3.1)$ & & $14(2.9)$ & & $8(1.7)$ & \\
\hline $1501-2000$ & $3(0.6)$ & & $13(2.7)$ & & $4(0.8)$ & \\
\hline$>2000$ & $54(11.2)$ & & $71(14.7)$ & & $46(9.5)$ & \\
\hline
\end{tabular}

Variation across lifetime cannabis use observed in students' living status and family monthly income. Lifetime cocaine use, the variation observed in sex, academic level, and living status (Table 3).

Age difference had no variation for last month's use of cannabis and cocaine ( $p$-value $=0.11$ vs. 0.6). All students with their different characteristics were equally practiced cannabis in the last month ( $p$ values were insignificant). Students' residence, academic level, currently living status, and family monthly income were not statistically significant in association with last month's cocaine use. This showed students with these predictor variables equally practiced cocaine use in the last month, (Table 4).

\section{Associated factors of lifetime legal substance use}

During bivariate analysis, a cut point of $p$-value less than 0.20 was used to export variables to multivariate analysis. These variables were exported to multivariable binary logistic regression. During multivariate analysis, six predictor variables became statistically significant factors of lifetime legal substances use $(P$-value $<0.05)$.

Among sociodemographic variables of the students, being male had a statistically significant association with 
Table 3 Last month legal drugs use and its correlation with students and family characteristics among Ataye TVET college students, Ethiopia, 2019

\begin{tabular}{|c|c|c|c|c|c|c|}
\hline \multirow[t]{2}{*}{ Variables } & \multicolumn{2}{|c|}{ Last month alcohol use } & \multicolumn{2}{|c|}{ Last month khat use } & \multicolumn{2}{|c|}{ Last month cigarette use } \\
\hline & Yes (\%) & $P$-value & Yes (\%) & $P$-value & Yes (\%) & $P$-value \\
\hline \multicolumn{7}{|c|}{ Age in years (quartile) } \\
\hline$<18$ & $3(0.6)$ & 0.001 & $2(0.4)$ & 0.001 & $2(0.4)$ & 0.001 \\
\hline $18-19.9$ & $27(5.6)$ & & $36(7.5)$ & & $19(3.9)$ & \\
\hline $20-21$ & $45(9.3)$ & & $67(13.9)$ & & $43(8.9)$ & \\
\hline$>21$ & $19(3.9)$ & & $18(3.7)$ & & 10() 2.1 & \\
\hline \multicolumn{7}{|l|}{ Sex } \\
\hline Male & $74(15.4)$ & 0.001 & $92(19.1)$ & 0.001 & 56 (11.6) & 0.001 \\
\hline Female & $20(4.1)$ & & $31(6.4)$ & & $18(3.7)$ & \\
\hline \multicolumn{7}{|l|}{ Residency } \\
\hline Urban & $90(18.7)$ & 0.90 & $119(24.7)$ & 0.400 & $71(9.1)$ & 0.80 \\
\hline Rural & $4(0.8)$ & & $4(0.8)$ & & $3(0.6)$ & \\
\hline \multicolumn{7}{|c|}{ Living years in the town } \\
\hline $1-5$ years & $41(8.5)$ & 0.01 & $50(10.4)$ & 0.001 & $29(6.0)$ & 0.01 \\
\hline $6-10$ & $12(2.5)$ & & $15(3.1)$ & & $7(1.4)$ & \\
\hline $11-15$ & $4(0.8)$ & & $5(1.0)$ & & $4(0.8)$ & \\
\hline $16-20$ & $18(3.7)$ & & $24(5.0)$ & & $19(3.9)$ & \\
\hline$>20$ & $19(3.9)$ & & $29(6.0)$ & & $15(3.1)$ & \\
\hline \multicolumn{7}{|l|}{ Academic level } \\
\hline level one & $23(4.8)$ & 0.001 & $22(4.6)$ & 0.001 & $11(2.3)$ & 0.001 \\
\hline level two & $17(3.5)$ & & $33(6.9)$ & & $21(4.4)$ & \\
\hline level three & $28(5.8)$ & & $44(9.1)$ & & $23(4.8)$ & \\
\hline level four & $26(5.4)$ & & $24(5.0)$ & & $19(3.9)$ & \\
\hline \multicolumn{7}{|l|}{ Currently living } \\
\hline Alone & $43(8.9)$ & 0.01 & $58(12.0)$ & 0.001 & $33(6.9)$ & 0.05 \\
\hline with family & $27(5.6)$ & & $33(6.9)$ & & $22(4.6)$ & \\
\hline with peers & $24(5.0)$ & & $32(6.6)$ & & $19(3.9)$ & \\
\hline \multicolumn{7}{|c|}{ Family income in ETB } \\
\hline$<1000$ & $8(1.7)$ & 0.001 & $8(1.7)$ & 0.001 & $5(1.0)$ & 0.001 \\
\hline 1001_1500 & $17(3.5)$ & & $21(4.4)$ & & $13(2.7)$ & \\
\hline 1501_2000 & $9(1.9)$ & & $14(2.9)$ & & $5(1.0)$ & \\
\hline$>2000$ & $60(12.5)$ & & $80(16.6)$ & & $51(10.6)$ & \\
\hline
\end{tabular}

lifetime legal substances use $(\mathrm{AOR}=2.2$ (95\% CI: 1.23 , 3.84). Males had two times higher odds to use legal substances in a lifetime (after joining college) as compared with females. Living more than 20 years in the town (Ataye) was almost four times higher odds of legal substances use at least once in a lifetime as compared with who lived $1-5$ years, $(\mathrm{AOR}=3.45,95 \% \mathrm{CI}$ : 1.18, 10.1). Students from divorced parents had four times higher odds to practice lifetime legal substance use as compared with married parents, $(\mathrm{AOR}=4.1,95 \% \mathrm{CI}: 1.78$, 9.30). Having a substance user family was a predictor of lifetime legal substance use. The odds of experiencing lifetime legal substance use were 2.5 times higher among students, who had a substance user family than those who don't have, $(\mathrm{AOR}=2.5,95 \% \mathrm{CI}: 1.1,5.8)$. Having an intimate friend who uses substance and easily availability of drugs in the Ataye town were also had a contribution to experience legal substances use in a lifetime, (AOR = 5.3, 95\% CI: 2.6, 10.9), and ( $\mathrm{AOR}=2.3,95 \% \mathrm{CI}: 1.2,4.4)$ respectively, (Table 5 ).

\section{Discussion}

Almost a third of the study participants experienced lifetime substance use and one-fifth use substance in the 
Table 4 Lifetime and last month illegal drugs use and its correlation with students and family characteristics among Ataye TVET college students, Ethiopia, 2019

\begin{tabular}{|c|c|c|c|c|c|c|c|c|}
\hline \multirow[t]{2}{*}{ Variables } & \multicolumn{2}{|c|}{ Lifetime cannabis use } & \multicolumn{2}{|c|}{ Lifetime cocaine use } & \multicolumn{2}{|c|}{ Last month cannabis use } & \multicolumn{2}{|c|}{ Last month cocaine use } \\
\hline & Yes (\%) & $P$-value & Yes (\%) & $P$-value & Yes (\%) & $p$-value & Yes (\%) & $p$-value \\
\hline \multicolumn{9}{|c|}{ Age in years (quartile) } \\
\hline$<18$ & $0(0.00)$ & 0.44 & $0(0.0)$ & 0.08 & $2(0.4)$ & 0.11 & $1(0.2)$ & 0.05 \\
\hline $18-19.9$ & $1(0.2)$ & & $4(0.8)$ & & $1(0.2)$ & & $11(2.3)$ & \\
\hline $20-21$ & $3(0.6)$ & & $10(2.0)$ & & $7(1.5)$ & & $19(3.9)$ & \\
\hline$>21$ & $2(0.4)$ & & $2(0.4)$ & & $2(0.4)$ & & $4(0.8)$ & \\
\hline \multicolumn{9}{|l|}{ Sex } \\
\hline Male & $4(0.8)$ & 0.40 & $15(3.0)$ & 0.001 & $8(1.6)$ & 0.20 & $31(6.4)$ & 0.001 \\
\hline Female & $2(0.4)$ & & $1(0.2)$ & & $4(0.8)$ & & $4(0.8)$ & \\
\hline \multicolumn{9}{|l|}{ Residence } \\
\hline Urban & $6(1.2)$ & 0.60 & $15(3.0)$ & 0.74 & $32(6.64)$ & 0.24 & $12(2.4)$ & 0.44 \\
\hline Rural & $0(0.00)$ & & $1(0.2)$ & & $3(0.6)$ & & $0(0.0)$ & \\
\hline \multicolumn{9}{|c|}{ Living years in the town } \\
\hline $1-5$ & $2(0.4)$ & 0.60 & $3(0.6)$ & 0.03 & $2(0.4)$ & 0.20 & $16(3.3)$ & 0.20 \\
\hline $6-10$ & $2(0.4)$ & & $3(0.6)$ & & $2(0.4)$ & & $6(1.2)$ & \\
\hline $11-15$ & $1(0.2)$ & & $1(0.2)$ & & $2(0.4)$ & & $1(0.2)$ & \\
\hline $16-20$ & $0(0.0)$ & & $4(0.8)$ & & $3(0.6)$ & & $5(1.0)$ & \\
\hline$>20$ & $1(0.2)$ & & $5(1.0)$ & & $3(0.6)$ & & $7(1.5)$ & \\
\hline \multicolumn{9}{|c|}{ Academic level } \\
\hline level one & $2(0.4)$ & 0.40 & $3(0.6)$ & 0.06 & $4(0.8)$ & 0.06 & $4(0.8)$ & 0.001 \\
\hline level two & $1(0.2)$ & & $6(1.2)$ & & $3(0.6)$ & & $12(2.4)$ & \\
\hline level three & $1(0.2)$ & & $7(1.5)$ & & $1(0.2)$ & & $13(2.7)$ & \\
\hline level four & $2(0.4)$ & & $0(0.0)$ & & $4(0.8)$ & & $6(1.2)$ & \\
\hline \multicolumn{9}{|c|}{ Currently living } \\
\hline Alone & $4(0.8)$ & 0.40 & $12(2.4)$ & 0.01 & $9(1.8)$ & 0.05 & $17(3.5)$ & 0.02 \\
\hline with family & $2(0.4)$ & & $1(0.2)$ & & $3(0.6)$ & & $7(1.5)$ & \\
\hline with peers & $0(0.0)$ & & $3(0.6)$ & & $0(0.0)$ & & $11(2.3)$ & \\
\hline \multicolumn{9}{|l|}{ Family income } \\
\hline$<1000$ & $1(0.2)$ & 0.50 & $1(0.2)$ & 0.20 & $1(0.2)$ & 0.05 & $2(0.6)$ & 0.08 \\
\hline 1001_1500 & $1(0.2)$ & & $3(0.6)$ & & $2(0.4)$ & & $9(1.8)$ & \\
\hline 1501_2000 & $0(0.0)$ & & $5(1.0)$ & & $0(0.0)$ & & $6(1.2)$ & \\
\hline$>2000$ & $4(0.4)$ & & $7(1.5)$ & & $9(1.8)$ & & $18(3.6)$ & \\
\hline
\end{tabular}

last month. Among lifetime legal substance users, nearly one-fourth chewed khat. Almost 20 and $15 \%$ use alcohol and cigarette after joining TVET College. Among last month's legal substance users, almost $22 \%$ chewed khat followed by alcohol drinking (16.6\%), and cigarette smoking (15.3\%).

Lifetime and last month smoking of cigarette were lower than studies from southern Iran [22] and Jimma University [23]. The possible explanation might be due to the health behavior of the students, and the target population's age difference.
Only two studies; one from Hawassa University [18] and another study from Gondar University [19] reported a similar prevalence (around 24\%) of lifetime khat chewing. The prevalence of lifetime khat chewing in the current study was lower than studies from Haramaya [24], and Jimma [23] universities. The possible reason might be due to the availability of khat in Haramaya and Jimma town is more prevalent than the current study area. Especially, Haramaya dwellers linked khat to the economy of the household and chewed khat as a habit [25]. This allows students to be easily exposed and 
Table 5 Bivariate and multivariate backward logistic regression analysis to identify associated factors with lifetime drug use among Ataye TVET students, Ethiopia, 2019

\begin{tabular}{|c|c|c|c|c|c|c|}
\hline \multirow[t]{2}{*}{ Variables } & \multicolumn{2}{|c|}{ Lifetime use } & \multirow[t]{2}{*}{ COR $(95 \% \mathrm{Cl})$} & \multirow{2}{*}{$\begin{array}{l}\text { COR } \\
p \text {-value }\end{array}$} & \multirow[t]{2}{*}{ AOR $(95 \% \mathrm{Cl})$} & \multirow{2}{*}{$\begin{array}{l}\text { AOR } \\
P \text {-value }\end{array}$} \\
\hline & $\overline{\text { Yes }}$ & No & & & & \\
\hline \multicolumn{7}{|l|}{ Sex } \\
\hline Male & 112 & 128 & $3.85(2.55,5.81)$ & 0.001 & $2.2(1.23,3.84)$ & 0.008 \\
\hline Female & 45 & 198 & 1.00 & & 1.00 & \\
\hline \multicolumn{7}{|l|}{ Years living in the town } \\
\hline $1-5$ & 70 & 138 & 1.00 & & 1.00 & \\
\hline $6-10$ & 19 & 77 & $0.49(0.27,0.87)$ & 0.001 & $0.81(0.33,2.00)$ & 0.644 \\
\hline $11-15$ & 7 & 33 & $0.42(0.18,0.99)$ & 0.031 & $0.5(0.15,1.66)$ & 0.260 \\
\hline $16-20$ & 29 & 63 & $0.91(0.54,1.54)$ & 0.12 & $0.53(0.21,1.33)$ & 0.180 \\
\hline$>20$ & 32 & 15 & $4.21(2.14,8.28)$ & 0.001 & $3.45(1.18,10.1)$ & 0.024 \\
\hline \multicolumn{7}{|l|}{ Parent marital status } \\
\hline Married & 88 & 288 & 1.00 & & 1.00 & \\
\hline Widowed/widower & 11 & 19 & $1.90(0.87,4.13$ & 0.029 & $1.13(0.37,3.44)$ & 0.830 \\
\hline Divorced & 58 & 19 & $9.99(5.65,17.67)$ & 0.001 & $4.1(1.78,9.3)$ & 0.001 \\
\hline \multicolumn{7}{|c|}{ Having substance user family } \\
\hline No & 85 & 306 & 1.00 & & 1.00 & \\
\hline Yes & 72 & 20 & $12.96(7.47,22.48)$ & 0.001 & $2.5(1.1,5.8)$ & 0.032 \\
\hline \multicolumn{7}{|c|}{ Having intimate friend substance user } \\
\hline No & 69 & 300 & 1.00 & & 1.00 & \\
\hline Yes & 88 & 26 & $14.72(8.84,24.5)$ & 0.001 & $5.3(2.6,10.9)$ & 0.001 \\
\hline \multicolumn{7}{|c|}{ Easily availability of substances } \\
\hline No & 43 & 261 & 1.00 & & 1.00 & \\
\hline Yes & 114 & 65 & $10.65(6.83,16.59)$ & 0.001 & $2.3(1.2,4.4)$ & 0.013 \\
\hline
\end{tabular}

Key: $C O R$ crude odds ratio, $A O R$ adjusted odds ratio

practiced khat. The prevalence of lifetime khat chewing was higher than studies done among Addis Ababa University, and Debre Berhan University. A possible explanation for the high prevalence of lifetime khat chewing in Ataye extends to social and environmental differences. First, khat is cultivated around Ataye town that could make it easy to access by students. All these factors can contribute to the practice of khat chewing among Ataye TVET students.

Last month khat chewing prevalence was lower than the study from the same study area [17] and Hawassa University [14]. Except for the study from south Iran [22], both last month and lifetime drinking of alcohol was lower than the studies from Jimma, Gondar, Debre Berhan, Hawassa University, and Woreta town [23, 26-28]. This might be due to social desirability bias, and increased abstinence rate in the past 30 days. Also, since the data collections have been done inside the teaching classroom, those students with addiction behaviors may remain outside the classroom because of their academic and living lifestyle. This can potentially introduce sampling bias and result in a lower estimate of alcohol drinking [18].
Male students had two times higher odds to use legal substances in their lifetime (after joining college) as compared with female students. The association is in agreement with studies done in Haramaya University [20], and Jimma University [23]. This association might be male students use substances than females due to cultural and hormonal differences [29-31].

Having substance user friends and family had higher odds to be exposed to legal substances used in a lifetime as compared with who has no legal substances user friend and family. The association is supported by studies done in Addis Ababa University [27], Debre Berhan University [32], Hawassa University [18], Grate Accra metropolis [33], and Woreta Town [28]. This might be due to, they may let students familiarize substances and adopt utilization thereby reducing the subjective norm and perceived risk perception of students [34]. Being from a divorced family also had a significant contribution to lifetime legal substance use as compared with students from married families. The study from Kuwait supports this association [35]. Many factors increase a young person's likelihood of substance use. Among 
them, parental divorce is the main factor. Parental conflicts and lack of supervision from parents is a known factor for young's health problem [36-39].

Easily availability of the substances was a statistically significant factor for lifetime substance use as compared with students from less substance accessibility areas. The possible reason might be, increased substance availability is associated with increased use [34]. In the study area, licit drugs are easily available; but not known about illicit drugs (cannabis and cocaine). At the study area (Ataye) and catchment areas, the community cultivates khat and this may put the study subjects at a greater risk of exposure.

Living 20 years and above in Ataye town had higher odds to be exposed to the lifetime legal substances as compared with those who lived $1-5$ years. This might be due to; living more years in one town might increase the exposure of the study participants to substances. More years needed to assimilate the community habit of substance use; even if it is two decades.

\section{Generalizability}

The external validity of the study was managed during a sample size calculation, sampling procedures, and techniques, training of data collectors, and data quality control sections.

\section{Limitations of the study}

There are several limitations to the present study. Firstly, self-reported substance use is likely underreported perhaps because of social desirability bias. Secondly, there is no means to verify the self-reports by biomarkers. Thirdly, the association shown from the cross-sectional study lacks temporal association. Lastly, the questionnaire used to assess the outcome and independent variables were not validated.

\section{Conclusions}

The prevalence of last month and lifetime legal substance use at Ataye Technical and Vocational Education and Training (TVET) college students were analogous with most studies done in Ethiopia. It is advisable if the college administrators work together with town administrators to mitigate the problem including closing substance use houses around the school. Overall, Substance use among adolescents should get further emphasis to lower the prevalence.

\section{Abbreviation}

TVET: Technical and vocational education and training

\section{Acknowledgments}

It is our pleasure to acknowledge the Amhara regional education bureau, Debre Berhan University, study health institutions, and the study participants.

\section{Authors' contributions}

AD: Analyze, and write up the thesis report. WN and SG: select the title, develop the proposal, and collect the data of the study. All the authors read and approved the final manuscript and agreed to be accountable for all aspects of the work.

\section{Funding}

The study was funded by the Amhara regional education bureau. The funder had no role in the designing of the study, data collection, analysis, interpretation of data, and writing of the manuscript.

\section{Availability of data and materials}

The datasets used and/or analyzed during the current study are available from the corresponding author on reasonable request.

\section{Ethics approval and consent to participate}

Ethical clearance obtained from the Debre Berhan University ethical review committee. Ethical clearance obtained from the Debre Berhan University ethical review committee. A letter of cooperation wrote to each study institution, and a permission letter taken from the study institutions. The data collectors took oral informed consent from each study participant, whose age is 18 years and above. Moreover, the data collectors took assent from participants whose age was less than 18 years. Written informed consent taken from participants' family/legal guardian whose age was less than 18 years.

\section{Consent for publication}

The manuscript did not contain individuals' person detailed data in any form.

\section{Competing interests}

The authors declare that they have no conflicts of interest.

\section{Author details}

${ }^{1}$ Department of Nursing, College of Health Science and Medicine, Debre Berhan University, P.O. Box 445, Debre Berhan, Ethiopia. ${ }^{2}$ Ataye General Hospital, North Shewa Zone, Addis Ababa, Amhara, Ethiopia.

Received: 14 September 2019 Accepted: 29 October 2020

Published online: 11 November 2020

\section{References}

1. Organization WH. Neuroscience of psychoactive substance use and dependence: World Health Organization; 2004.

2. Lubman DI, Yucel M. Adolescent substance use and the developing brain. Dev Med Child Neurol. 2008;50(1):76.

3. Silveri MM, Dager AD, Cohen-Gilbert JE, Sneider JT. Neurobiological signatures associated with alcohol and drug use in the human adolescent brain. Neurosci Biobehav Rev. 2016;70:244-59.

4. Merz F. United Nations Office on drugs and crime: world drug report 2017. SIRIUS-Zeitschrift Strategische Analysen. 2018;2(1):85-6.

5. Drugs UOo, Crime. World Drug Report 2015. 2015.

6. EDHS ED. Health survey. Key indicators report 2016.

7. Blum RH. Students and drugs: Jossey-Bass; 1969.

8. Flowers RB. College crime: a statistical study of offenses on American campuses: McFarland; 2009.

9. Bean P. Drugs and crime: Routledge; 2014.

10. Bachman JG, Schulenberg JE, Freedman-Doan P, O'Malley PM, Johnston LD, Messersmith EE. The education-drug use connection: how successes and failures in school relate to adolescent smoking, drinking, drug use, and delinquency: Psychology Press; 2008.

11. Andrade FH. Co-occurrences between adolescent substance use and academic performance: school context influences a multilevel-longitudinal perspective. J Adolesc. 2014;37(6):953-63.

12. Plant M. Risk-takers: alcohol, drugs, sex, and youth: Routledge; 2002.

13. Schulenberg J, Maggs JL, Hurrelmann K. Health risks, and developmental transitions during adolescence: Cambridge University press; 1999.

14. Sebsibie G. Assessment of drug addiction and its associated factor among youths in Nazareth town, Eastern Shoa, Ethiopia. J Addict Res Ther. 2018;9(356):2.

15. Tulu SK, Keskis W. Assessment of causes, prevalence, and consequences of alcohol and drug abuse among Mekelle University, CSSL 2nd year students. Am J Appl Psychol. 2015:3:47-56. 
16. Mohammed AY. Assessment of substance use and associated factors among high school and preparatory school students of Ginnir town, bale zone, Southeast Ethiopia. Am J Health Res. 2014;2(6):414-9.

17. Lakew A, Tariku B, Deyessa N, Reta Y. Prevalence of Catha edulis (khat) chewing and its associated factors among ataye secondary school students in northern shoa, Ethiopia. Adv Appl Sociol. 2014;4(10):225.

18. Kassa A, Wakgari N, Taddesse F. Determinants of alcohol use and khat chewing among Hawassa University students, Ethiopia: a cross sectional study. Afr Health Sci. 2016;16(3):822-30.

19. Fufa G, Shiferaw D, Kinati T, Desalegn M. The nexus between khat and other drug use among undergraduate students of Jigjiga University in Ethiopia; contributing factors and prevalence rates. Public Health Res. 2017;7(2):49-54

20. Tesfaye G, Derese A, Hambisa MT. Substance use and associated factors among university students in Ethiopia: a cross-sectional study. J Addict. 2014;2014.

21. Organization WH. The ASSIST screening test version 3.0 and feedback card: WHO World Health Organization; 2015.

22. Heydari ST, Izedi S, Sarikhani Y, Kalani N, Akbary A, Miri A, et al. The prevalence of substance use and associated risk factors among university students in the city of Jahrom, Southern Iran. Int J High Risk Behav Addict. 2015;4(2).

23. Meressa K, Mossie A, Gelaw Y. Effect of substance use on academic achievement of health officer and medical students of Jimma University, Southwest Ethiopia. Ethiop J Health Sci. 2009;19(3)

24. Derese A, Seme A, Misganaw C. Assessment of substance use and risky sexual behaviour among Haramaya University students, Ethiopia. Sci J Public Health. 2014:2(2):102-10.

25. Gebissa E. Leaf of Allah: khat \& agricultural transformation in Harerge, Ethiopia 1875-1991: Ohio State University Press; 2004.

26. Mamo DB, Abuhay DA, Gelaw BK, Tegegne GT. Assessment on the prevalence and contributing factors of social drugs utilization among university of Gondar regular undergraduate students, maraki campus, 2013. View Article 2014

27. Deressa W, Azazh A. Substance use and its predictors among undergraduate medical students of Addis Ababa University in Ethiopia. BMC Public Health. 2011;11(1):660

28. Birhanu AM, Bisetegn TA, Woldeyohannes SM. High prevalence of substance use and associated factors among high school adolescents in Woreta town, Northwest Ethiopia: multi-domain factor analysis. BMC Public Health. 2014;14(1):1186.

29. Brady KT, Randall CL. Gender differences in substance use disorders. Psychiatr Clin N Am. 1999;22(2):241-52.

30. Drapalski A, Bennett M, Bellack A. Gender differences in substance use, consequences, motivation to change, and treatment seeking in people with serious mental illness. Subst Use Misuse. 2011;46(6):808-18.

31. Durrant R, Thakker J. Substance use and abuse: cultural and historical perspectives: Sage; 2003.

32. Gebremariam TB, Mruts KB, Neway TK. Substance use and associated factors among Debre Berhan University students, Central Ethiopia. Subst Abuse Treat Prev Policy. 2018;13(1):13.

33. Oyedele V, Chikwature W, Oyedele O, Kadenha C. Drug abuse and its academic implications among students at three secondary schools in mutasa central area of mutasa district. Eur J Educ Stud. 2016.

34. Thomas YF, Richardson D, Cheung I. Geography and drug addiction: Springer Science \& Business Media; 2008.

35. Bajwa HZ, Al-Turki AS, Dawas AM, Behbehani MQ, Al-Mutairi AM, AlMahmoud S, et al. Prevalence and factors associated with the use of illicit substances among male university students in Kuwait. Med Princ Pract. 2013;22(5):458-63.

36. Johnson V, Pandina RJ. Effects of the family environment on adolescent substance use, delinquency, and coping styles. Am J Drug Alcohol Abuse. 1991;17(1):71-88.

37. Arkes J. The temporal effects of parental divorce on youth substance use. Subst Use Misuse. 2013;48(3):290-7.

38. Doherty WJ, Needle RH. Psychological adjustment and substance use among adolescents before and after a parental divorce. Child Dev. 1991;62(2):328-37.

39. Neher LS, Short JL. Risk and protective factors for children's substance use and antisocial behavior following parental divorce. Am J Orthop. 1998;68(1): 154-61.

\section{Publisher's Note}

Springer Nature remains neutral with regard to jurisdictional claims in published maps and institutional affiliations.

\section{Ready to submit your research? Choose BMC and benefit from:}

- fast, convenient online submission

- thorough peer review by experienced researchers in your field

- rapid publication on acceptance

- support for research data, including large and complex data types

- gold Open Access which fosters wider collaboration and increased citations

- maximum visibility for your research: over $100 \mathrm{M}$ website views per year

At BMC, research is always in progress.

Learn more biomedcentral.com/submissions 